\title{
Intraductal simethicone application for optimization of endoscopic view on direct cholangioscopy
}

\author{
Vincent Zimmer ${ }^{\mathrm{a}, \mathrm{b}}$ \\ Marienhausklinik St. Josef Kohlhof, Neunkirchen; Saarland University Medical Center, Homburg, Germany
}

Direct cholangioscopy (DC) using ultra-slim upper endoscopes has gained wide appreciation for its high-quality visualization of the biliary tract. As opposed to single-operator cholangioscopy, associated with lower visual quality but more technical ease of use, successful DC is dependent on adequate bile duct diameters and a wider-bore papillary access by, for example, maximum-incision papillotomy and/or balloon dilation. This, however, often results in exuberant spontaneous pneumobilia, which, in turn, is notorious for greatly reducing the quality of endoscopic visualization in any gastrointestinal application. Against this background, and despite increasing hygiene concerns related to endoscope re-processing, the utilization of simethicone, a silicone-based polymer, to reduce foam and air bubbles is routine in endoscopy practice; however, it has not been specifically reported for cholangioscopy purposes.

Here we report the case of an elderly female patient undergoing an uncomplicated cholangioscopy-guided electrohydraulic lithotripsy (EHL) under peri-interventional antibiotics using ceftriaxone. Because of her markedly dilated biliary system, neither $\mathrm{CO}_{2}$ nor water instillation was warranted during ultra-slim DC after freehand access in the "J maneuver" technique [1,2]. After reinsertion of the upper endoscope following EHL fragment extractions by conventional endoscopic retrograde cholangiography technology, high-quality cholangioscopic visualization of the hilum was impeded by multiple air bubbles (Fig. 1). After intraductal cleansing with a sterile saline/simethicone mixture applied through a small-sheath catheter, the interference from air bubbles was resolved, allowing fullscale endoscopic assessment of the biliary mucosa (Fig. 2). Notwithstanding that the potential clinical utility of simethicone for improvement of mucosal assessment might be applicable to all endoscopy procedures, this is the first specific report on simethicone use during DC [3].

${ }^{a}$ Department of Medicine, Marienhausklinik St. Josef Kohlhof, Neunkirchen, Germany (Vincent Zimmer); ${ }^{b}$ Department of Medicine II, Saarland University Medical Center, Saarland University, Homburg (Vincent Zimmer), Germany

\section{Conflict of Interest: None}

Correspondence to: Dr. Vincent Zimmer, Department of Medicine, Marienhausklinik St. Josef Kohlhof, Klinikweg 1-5, 66539 Neunkirchen, Germany, e-mail: vincent.zimmer@gmx.de

Received 2 June 2020; accepted 4 June 2020; published online 30 June 2020

DOI: https://doi.org/10.20524/aog.2020.0512

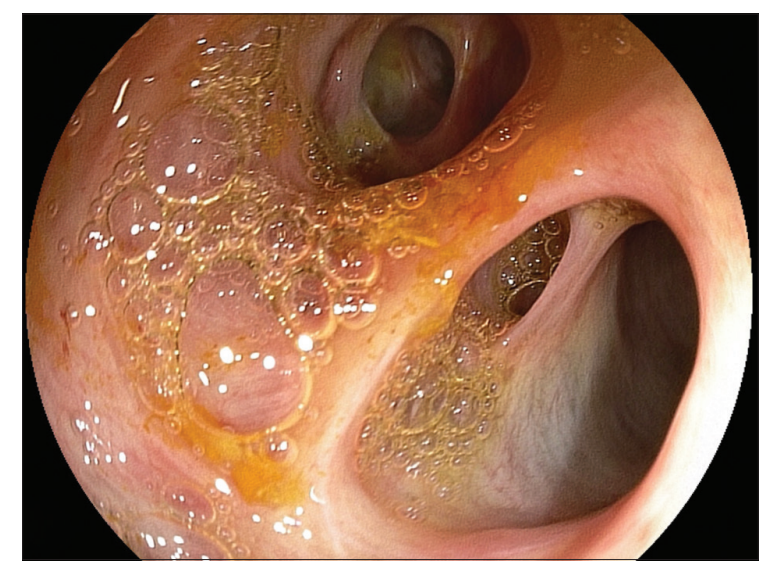

Figure 1 High-quality cholangioscopic view of the hilum after freehand intubation of an ultra-slim upper endoscope is impeded by an exuberance of air bubbles

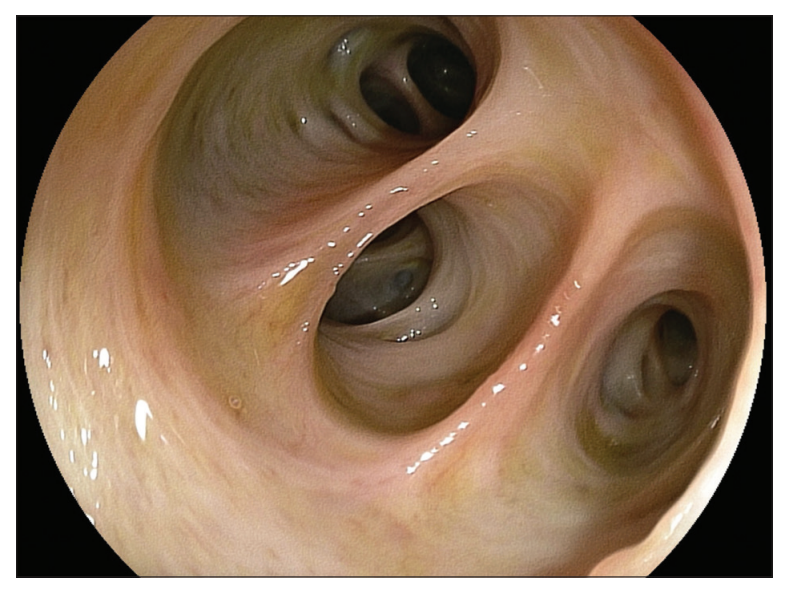

Figure 2 Extensive intraductal cleansing using a sterile/simethicone mixture applied though a small-sheath catheter provided a full-scale endoscopic visualization of the biliary mucosa

\section{References}

1. Brauer BC, Chen YK, Shah RJ. Single-step direct cholangioscopy by freehand intubation using standard endoscopes for diagnosis and therapy of biliary diseases. Am J Gastroenterol 2012;107:10301035.

2. Zimmer V, Lammert F. Positioning cholangioscopy in bile duct stone management: mind the technology gap. Frontline Gastroenterol 2018;9:315-316.

3. Devereaux BM, Taylor ACF, Athan E, et al. Simethicone use during gastrointestinal endoscopy: Position statement of the Gastroenterological Society of Australia. J Gastroenterol Hepatol 2019;34:2086-2089. 